\title{
Workover String Mechanical Model and Calculation of Slanted and Horizontal Well
}

\author{
Bingguo Du1,2, Hanqiao Jiang1 \\ ${ }^{1}$ China University of Petroleum School of Petroleum Engineering, Beijing, China \\ ${ }^{2}$ Sinopec Shengli Oilfield, Dongying, China \\ Email: dubingguo.slyt@sinopec.com
}

Received 4 May 2015; accepted 24 May 2015; published 27 May 2015

Copyright (C) 2015 by authors and Scientific Research Publishing Inc.

This work is licensed under the Creative Commons Attribution International License (CC BY).

http://creativecommons.org/licenses/by/4.0/

(c) (;) Open Access

\begin{abstract}
Force analysis and calculation of workover string in the slanted and horizontal well are the basis of designing and checking string strength, selecting tools and determining operation parameters, which determine the operation safety and success of engineering accidence treatment. In this paper, by comprehensive consideration of wellbore structure, string assembly, string load and workover operation conditions, the workover string mechanical model has been built under three kinds of working states of lifting, lowering and rotating. The downhole string mechanics has been analyzed and calculated. By field verification, the string assembly, tool selection and operation parameter optimization can be achieved, which can improve the safety and success rates of workover engineering accident treatment.
\end{abstract}

\section{Keywords}

Slanted Well, Horizontal Well, Workover String, Mechanics Model, Torque, Accident Treatment

\section{Introduction}

The casing in slanted and horizontal well is curved, so by the limits of the casing workover string is curved. It makes workover string not only by the force of its own gravity, but also by the friction between the casing and workover string as well as the torque caused by friction [1]. Some conventional processing tools, appliance and treatment methods cannot satisfy the need of accident treatment in the process of engineering accident, and it even makes the engineering accident more complicated.

As a result, workover string mechanical model is established according to the characteristics of slanted and horizontal well. Stress analysis and calculation can guide the field construction, which has an important meaning to improve the safety and success rates of workover engineering accident treatment. 


\section{Workover String Mechanical Model of Slanted and Horizontal Well}

In the workover string force analysis of the slanted and horizontal wells, the tubing string is the analysis object, the string is taken as flexible pole to analyze its stress, and the mechanical models of workover string under lifting, lowering and rotating states are established.

\subsection{The Mechanical Model of Lifting State}

Figure 1 is the mechanical model of string when lifting it in the uniform rate. The string is basically in a vertical state above the kickoff point $\mathrm{A}$, and begin to contact with casing below the point A (approximately beginning with point $\mathrm{A}$ ), until the point $\mathrm{B}$, the string divides with the casing. Because of the gravity the string gradually becomes vertical with the casing. The string is contacted with the bottom of casing from the kickoff end point $\mathrm{C}$ to the casing bottom. Because the distance between the point $\mathrm{B}$ and $\mathrm{C}$ is very short, it can be considered as a point [2]. The force on the string is as follows:

1) The pulling force of the string (hook hoisting load) $F_{1}$;

2) The weight of the string above the deflection point $G_{1}$;

3) The weight of the string with the friction tape of casing $A B$ is $G_{2}$ and the friction force between the string and casing $f_{1}$;

4) The weight of the string below the point $C$ is $G_{3}$ and the friction force between the string and the casing is $f_{2}$;

5) The anchorage force of the string with the friction tape of casing $\mathrm{AB}$ as well as below is $F_{2}$ and $F_{3}$;

6) The pulling force $F$ to the bottom of the string by the fish, for 0 when the fish is not retrieved.

The relationships of the forces are as follows:

$$
\begin{gathered}
F_{1}=G_{1}+G_{2} \cdot \cos \frac{\alpha}{2}+f_{1}+G_{3} \cdot \cos \alpha+f_{2}+F \\
f_{1}=F_{2} \cdot \mu, f_{2}=F_{3} \cdot \mu, F_{3}=G_{3} \cdot \sin \alpha \\
F_{2}=\frac{\left(G_{2} \cdot \cos \frac{\alpha}{2}+G_{3} \cdot \cos \alpha+G_{3} \cdot \sin \alpha \cdot \mu\right) \sqrt{2(1-\cos \alpha)}-G_{2} \cdot \sin \frac{\alpha}{2}}{1-\sqrt{2(1-\cos \alpha)} \cdot \mu} \text { (when fish is not retrieved) } \\
F_{2}=\left(F_{1}-G_{1}\right) \sqrt{2(1-\cos \alpha)}-G_{2} \cdot \sin \frac{\alpha}{2} \text { (when fish is retrieved and jam is released) }
\end{gathered}
$$

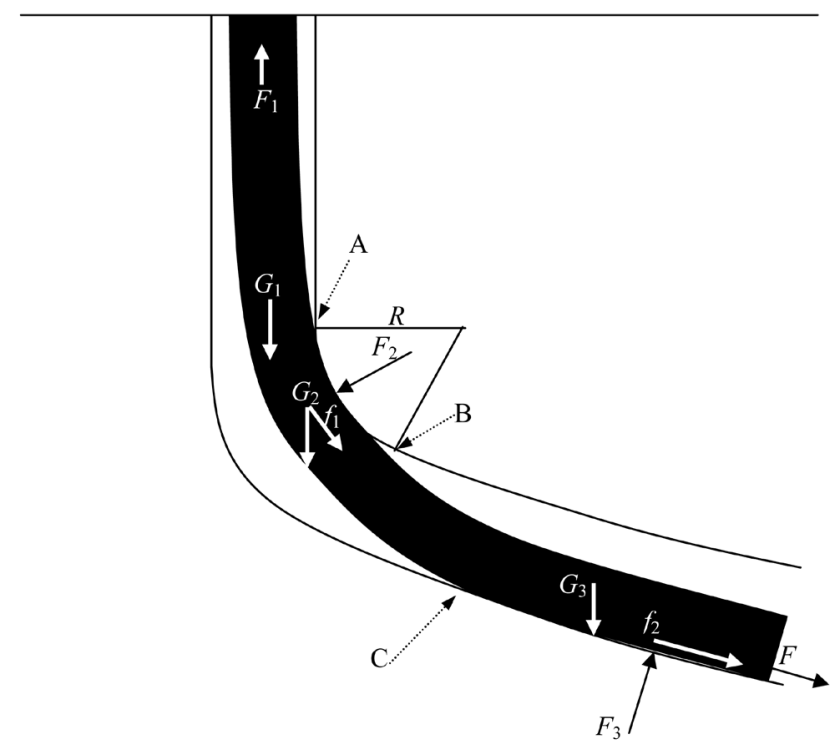

Figure 1. The mechanical model of string in lifting state. 
At this time,

$$
\begin{gathered}
F=F_{1}-G_{1}-G_{2} \cdot \cos \frac{\alpha}{2}-F_{2} \cdot \mu-G_{3} \cdot \cos \alpha-G_{3} \cdot \sin \alpha \cdot \mu \\
G_{1}=w \cdot L_{1}, \quad G_{2}=w \cdot L_{2}, \quad G_{3}=w \cdot L_{3}
\end{gathered}
$$

$\alpha$-the maximum degree of slope;

$w$ - the unit weight of the string in the wellbore, $\mathrm{N} / \mathrm{m}$;

$L_{1}$ - the length of the vertical string, $m$;

$L_{2}$ - the length of the kickoff string, $\mathrm{m}$;

$L_{3}$ - the length of the slanted string, $\mathrm{m}$;

$\mu$-the friction coefficient between the string and casing.

\subsection{The Mechanical Model of Lowering State}

Figure 2 is the force state of string in lowering state. At the uniform lowering state, the bending of the string is almost the same with the lifting state except the point B moved up [3]. The force on the string is as follows:

1) The pulling force of the string (hook hoisting load) $F_{1}$;

2) The weight of the string above the deflection point $G_{1}$;

3) The weight of the string with the friction tape of casing $\mathrm{AB}$ is $G_{2}$ and the friction force between the string and casing $f_{1}$;

4) The weight of the string below the point $\mathrm{C}$ is $G_{3}$ and the friction force between the string and the casing is $f_{2}$;

5) The anchorage force of the string with the friction tape of casing $\mathrm{AB}$ as well as below is $F_{2}$ and $F_{3}$.

The relationships of the forces are as follows:

$$
\begin{gathered}
F_{1}=G_{1}+G_{2} \cdot \cos \frac{\alpha}{2}-f_{1}+G_{3} \cdot \cos \alpha-f_{2} \\
f_{1}=F_{2} \cdot \mu, \quad f_{2}=F_{3} \cdot \mu, \quad F_{3}=G_{3} \cdot \sin \alpha \\
F_{2}=\frac{\left(G_{2} \cdot \cos \frac{\alpha}{2}+G_{3} \cdot \cos \alpha-G_{3} \cdot \sin \alpha \cdot \mu\right) \sqrt{2(1-\cos \alpha)}-G_{2} \cdot \sin \frac{\alpha}{2}}{1-\sqrt{2(1-\cos \alpha)} \cdot \mu} \\
G_{1}=w \cdot L_{1}, \quad G_{2}=w \cdot L_{2}, \quad G_{3}=w \cdot L_{3}, \quad G_{4}=w \cdot L_{4}, \quad L_{2}=\frac{\alpha_{B}}{\alpha} L_{0}
\end{gathered}
$$

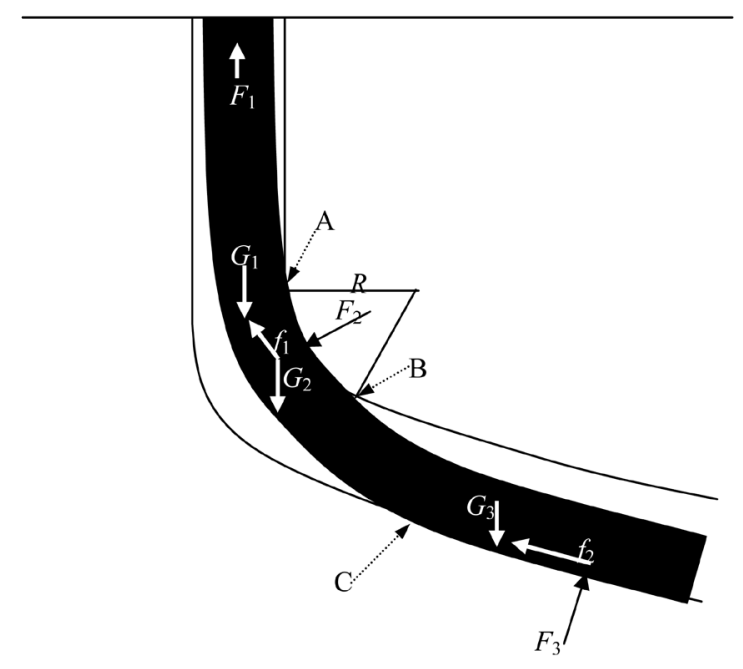

Figure 2. The mechanical model of string in lowering state. 


\subsection{The Mechanical Model of Rotating State}

Figure 3 is the force and moment of the string in circulate state. Because of the circulation, the axial friction force of the string is 0 . The friction force mainly causes the counter torque $T_{1}$ and $T_{2}$ opposite to the moment of the wellhead [4].

1) The pulling force of the string (hook hoisting load) $F_{1}$;

2) The weight of the string above the deflection point $G_{1}$;

3) The weight of the string with the friction tape of casing $\mathrm{AB}$ is $G_{2}$ and the friction force between the string and casing $f_{1}$ as well as the moment $T_{1}$ caused by $f_{1}$;

4) The weight of the string below the point $C$ is $G_{3}$ and the friction force between the string and the casing is $f_{2}$ as well as the moment $T_{2}$ caused by $f_{2}$;

5) The anchorage force of the string with the friction tape of casing $\mathrm{AB}$ as well as below is $F_{2}$ and $F_{3}$;

6) The pulling force $F$ to the bottom of the string by the fish.

The relationships of the forces are as follows:

$$
\begin{gathered}
F_{1}=G_{1}+G_{2} \cdot \cos \frac{\alpha}{2}+G_{3} \cdot \cos \alpha+F \\
f_{1}=F_{2} \cdot \mu, \quad f_{2}=F_{3} \cdot \mu, \quad F_{3}=G_{3} \cdot \sin \alpha \\
F_{2}=\left(F_{1}-G_{1}\right) \sqrt{2(1-\cos \alpha)}-G_{2} \cdot \sin \frac{\alpha}{2} \\
F=F_{1}-G_{1}-G_{2} \cdot \cos \frac{\alpha}{2}-G_{3} \cdot \cos \alpha \\
G_{1}=w \cdot L_{1}, G_{2}=w \cdot L_{2}, G_{3}=w \cdot L_{3} \\
T_{1}=f_{1} \cdot \frac{d}{2}, T_{2}=f_{2} \cdot \frac{d}{2}, T=T_{1}+T_{2}+T_{3}
\end{gathered}
$$

$\mathrm{T}$ - Torque provided by the power equipment on well head, $(\mathrm{N} \cdot \mathrm{m})$;

$T_{1}$ - Torque caused by $f_{1},(\mathrm{~N} \cdot \mathrm{m})$;

$\mathrm{T}_{2}$ - Torque caused by, $(\mathrm{N} \cdot \mathrm{m})$;

$\mathrm{T}_{3}$ - Torque that wellhead torque transfer to the fish after overcoming friction torque, $(\mathrm{N} \cdot \mathrm{m})$;

$d$-Outer diameter of string where friction takes place, (m).

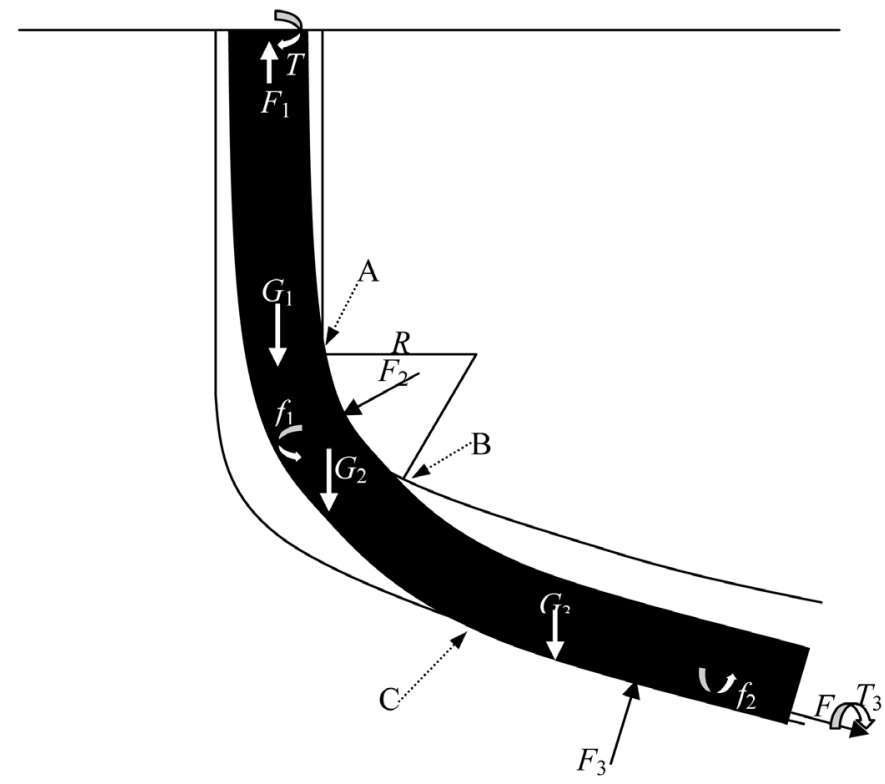

Figure 3. The mechanical model of string in rotating state. 


\section{The Calculation of the Force and Moment in Well ST32131 String}

Well ST32131 is a new fractured well constructed by some job team. The string falls to well in the process of sand washing after fracture, fish top is $73 \mathrm{~mm}$ pipe couplings, depth is $2682.31 \mathrm{~m}$, the length of fish is $710 \mathrm{~m}$. Now the force of the well in the salvage construction and the torque of the string in rotating state are analyzed and calculated [5]. The results are as follows:

\subsection{The Condition of the Well}

The string salvaged in well is the string assembly of $89 \mathrm{~mm}$ and $73 \mathrm{~mm}$ (outer thickening) of N80, the length is $1182 \mathrm{~m}$ and $1500 \mathrm{~m}$. Known that the weight of $89 \mathrm{~mm}$ tubing in well is $117.6 \mathrm{~N} / \mathrm{m}$, and $73 \mathrm{~mm}$ outer thickening tubing is $83.5 \mathrm{~N} / \mathrm{m}$ (density of well liquid is $1.0 \mathrm{~g} / \mathrm{cm}^{3}$ ), and the fish in well is of $73 \mathrm{~mm}$ tubing of $\mathrm{J} 55$, the weight is $81.5 \mathrm{~N} / \mathrm{m}$.

1) Base data (Table 1).

2) The base data about the string assembly of $89 \mathrm{~mm}$ and $73 \mathrm{~mm}$ (outer thickening) of N80 (Table 2).

\subsection{Known Conditions}

$\alpha=37.5^{\circ}, \quad L_{1}=1417.2 \mathrm{~m}, \quad L_{2}=784 \mathrm{~m}, \quad L_{3}=481.1 \mathrm{~m}, \quad \mu=0.15, \quad w_{89}=117.6 \mathrm{~N} / \mathrm{m}, \quad w_{73 \text { up }}=83.5 \mathrm{~N} / \mathrm{m}$, $w_{73}=81.5 \mathrm{~N} / \mathrm{m}, \quad d=73 \mathrm{~mm}=0.073 \mathrm{~m}, \mu=0.4$.

According to the above conditions the following can be worked out [6].

$G_{1}=158.6 \mathrm{kN}, G_{2}=65.5 \mathrm{kN}, G_{3}=40.2 \mathrm{kN}, \sin \alpha=0.61, \cos \alpha=0.79, \quad \cos \frac{\alpha}{2}=0.95, \quad \sin \frac{\alpha}{2}=0.32$.

\subsection{At the Lifting State}

1) Before fish is retrieved $F=0$, and

$$
\begin{gathered}
F_{2}=\frac{\left(G_{2} \cdot \cos \frac{\alpha}{2}+G_{3} \cdot \cos \alpha+G_{3} \cdot \sin \alpha \cdot \mu\right) \sqrt{2(1-\cos \alpha)}-G_{2} \cdot \sin \frac{\alpha}{2}}{1-\sqrt{2(1-\cos \alpha)} \cdot \mu}=62.8(\mathrm{kN}) \\
f_{1}=F_{2} \cdot \mu=25.1(\mathrm{kN}) \\
F_{1}=G_{1}+G_{2} \cdot \cos \frac{\alpha}{2}+f_{1}+G_{3} \cdot \cos \alpha+f_{2}=287.5(\mathrm{kN}) .
\end{gathered}
$$

\begin{tabular}{|c|c|c|c|c|c|}
\hline $\begin{array}{l}\text { Casing external } \\
\text { diameter }\end{array}$ & $139.7 \mathrm{~mm}$ & Casing thickness & 9.17 mm & Casing depth & $3410.0 \mathrm{~m}$ \\
\hline Drilled depth & $3416.0 \mathrm{~m}$ & Cement return height & Wellhead & Cement quality & Qualified \\
\hline $\begin{array}{l}\text { Artificial botoum } \\
\text { hole }\end{array}$ & $3394.4 \mathrm{~m}$ & Fish top depth & $2682.31 \mathrm{~m}$ & $\begin{array}{l}\text { Distance between tubing } \\
\text { and bushing }\end{array}$ & $4.72 \mathrm{~m}$ \\
\hline Kickoff point & $1417.2 \mathrm{~m}$ & Biggest inclined point & $2201.2 \mathrm{~m}$ & Maximum angle & $37.49^{\circ}$ \\
\hline
\end{tabular}

2) When fish is retrieved and jam is released $600 \mathrm{kN}$,

Table 1. The base data of well ST32131.

\begin{tabular}{|c|c|c|c|c|c|c|c|c|c|c|c|}
\hline \multirow{2}{*}{ Tubing } & \multirow{2}{*}{$\begin{array}{c}\text { External } \\
\text { diameter/(mm) }\end{array}$} & \multirow{2}{*}{$\begin{array}{l}\text { thickness/ } \\
\text { (mm) }\end{array}$} & \multirow{2}{*}{$\begin{array}{c}\text { Inner } \\
\text { diameter/ } \\
(\mathrm{mm})\end{array}$} & \multirow{2}{*}{ Grade } & \multirow{2}{*}{$\begin{array}{l}\text { weight/ } \\
\text { (N/m) }\end{array}$} & \multirow{2}{*}{$\begin{array}{l}\text { volume/ } \\
(\mathrm{L} / \mathrm{m})\end{array}$} & \multirow{2}{*}{$\begin{array}{l}\text { tensile } \\
\text { strength/ } \\
(\mathrm{kN})\end{array}$} & \multirow{2}{*}{$\begin{array}{l}\text { Coupling } \\
\mathrm{OD} /(\mathrm{mm})\end{array}$} & \multicolumn{3}{|c|}{ Buckled torque/(N·m) } \\
\hline & & & & & & & & & minimum & best & maximum \\
\hline 89 & 88.9 & 6.5 & 76.0 & N80 & 134 & 1.67 & 708 & 107 & 2150 & 2850 & 3600 \\
\hline 73UP & 73.02 & 5.5 & 62.0 & N80 & 95 & 1.17 & 645 & 93 & 2400 & 3200 & 4000 \\
\hline 73 & 73.02 & 5.5 & 62.0 & J55 & 93 & 1.17 & 323 & 89 & 1100 & 1450 & 1800 \\
\hline
\end{tabular}

Table 2. The base data of tubing used to salvage. 


$$
\begin{gathered}
F_{2}=\left(F_{1}-G_{1}\right) \sqrt{2(1-\cos \alpha)}-G_{2} \cdot \sin \frac{\alpha}{2}=266.0(\mathrm{kN}) \\
F=F_{1}-G_{1}-G_{2} \cdot \cos \frac{\alpha}{2}-F_{2} \cdot \mu-G_{3} \cdot \cos \alpha-G_{3} \cdot \sin \alpha \cdot \mu=231.2(\mathrm{kN})
\end{gathered}
$$

\subsection{At the Lowering State}

$$
\begin{gathered}
F_{2}=\frac{\left(G_{2} \cdot \cos \frac{\alpha}{2}+G_{3} \cdot \cos \alpha-G_{3} \cdot \sin \alpha \cdot \mu\right) \sqrt{2(1-\cos \alpha)}-G_{2} \cdot \sin \frac{\alpha}{2}}{1-\sqrt{2(1-\cos \alpha)} \cdot \mu}=45.6(\mathrm{kN}) \\
F_{1}=G_{1}+G_{2} \cdot \cos \frac{\alpha}{2}-f_{1}+G_{3} \cdot \cos \alpha-f_{2}=224.5(\mathrm{kN})
\end{gathered}
$$

\subsection{At Natural Rotation in Uniform Rate}

1) Naturally rotating the string before salvaging fish, at this time

$$
\begin{gathered}
F=F_{1}-G_{1}-G_{2} \cdot \cos \frac{\alpha}{2}-G_{3} \cdot \cos \alpha=0, \text { so } F_{1}=252.6(\mathrm{kN}) \\
F_{2}=\left(F_{1}-G_{1}\right) \sqrt{2(1-\cos \alpha)}-G_{2} \cdot \sin \frac{\alpha}{2}=40.1(\mathrm{kN}) \\
T_{1}=f_{1} \cdot \frac{d}{2}=F_{2} \cdot \mu \cdot \frac{d}{2}=586.0(\mathrm{~N} \cdot \mathrm{m}) \\
T_{2}=f_{2} \cdot \frac{d}{2}=G_{3} \cdot \sin \alpha \cdot \mu \cdot \frac{d}{2}=281.0(\mathrm{~N} \cdot \mathrm{m}) \\
T_{1}+T_{2}=586.0+281.0=867(\mathrm{~N} \cdot \mathrm{m})
\end{gathered}
$$

2) When salvaging tubing and picking up $300 \mathrm{kN}$ to back off,

$$
\begin{gathered}
F_{2}=\left(F_{1}-G_{1}\right) \sqrt{2(1-\cos \alpha)}-G_{2} \cdot \sin \frac{\alpha}{2}=71.0(\mathrm{kN}) \\
T_{1}=f_{1} \cdot \frac{d}{2}=F_{2} \cdot \mu \cdot \frac{d}{2}=1036.6(\mathrm{~N} \cdot \mathrm{m}) \\
T_{2}=f_{2} \cdot \frac{d}{2}=G_{3} \cdot \sin \alpha \cdot \mu \cdot \frac{d}{2}=281.0(\mathrm{~N} \cdot \mathrm{m}) \\
T_{1}+T_{2}=1036.6+281.0=1317.6(\mathrm{~N} \cdot \mathrm{m})
\end{gathered}
$$

3) If back off from the bottom of fish (fall fish is buried by sand)

$$
\begin{gathered}
F=G \cdot \cos \alpha=w_{73} \cdot L \cdot \cos \alpha=45706(\mathrm{~N})=45.7(\mathrm{kN}) \\
F_{2}=\frac{\left(G_{2} \cdot \cos \frac{\alpha}{2}+G_{3} \cdot \cos \alpha+F\right) \sqrt{2(1-\cos \alpha)}-G_{2} \cdot \sin \frac{\alpha}{2}}{1-\sqrt{2(1-\cos \alpha)} \cdot \mu}=94.4(\mathrm{kN}) \\
T_{1}=f_{1} \cdot \frac{d}{2}=F_{2} \cdot \mu \cdot \frac{d}{2}=1378.2(\mathrm{~N} \cdot \mathrm{m}) \\
T_{2}=f_{2} \cdot \frac{d}{2}=G_{3} \cdot \sin \alpha \cdot \mu \cdot \frac{d}{2}=281(\mathrm{~N} \cdot \mathrm{m})
\end{gathered}
$$




$$
\begin{gathered}
T_{2}^{\prime}=f_{2} \cdot \frac{d}{2}=\left(G_{3} \cdot \sin \alpha \cdot \mu+G \cdot \sin \alpha \cdot \mu\right) \cdot \frac{d}{2}=685.6(\mathrm{~N} \cdot \mathrm{m}) \\
T_{1}+T_{2}=1378.2+281.0=1659.2(\mathrm{~N} \cdot \mathrm{m}) \\
T_{1}+T_{2}^{\prime}=1378.2+685.6=2063.8(\mathrm{~N} \cdot \mathrm{m})
\end{gathered}
$$

$T_{2}^{\prime}$ — the sum of counter torque generated by the string lower friction part and fish.

\section{The Results and the Field Tests}

1) The load of uniformly lifting the string is $287.5 \mathrm{kN}$, while the load of lowering it is $224.5 \mathrm{kN}$, so the difference of the two loads is $63 \mathrm{kN}$; the solution force got by fish top is $231.2 \mathrm{kN}$ when jam is released to $600 \mathrm{kN}$, the load loss is $81.3 \mathrm{kN}$ and it accounts for a quarter of the rise load.

2) The torque that can make string rotate uniformly is calculated to be $1104.5 \mathrm{~N} \cdot \mathrm{m}$, with the carry load increasing, the friction torque of string also increases, that has effects on string's back-off and leads to a wrong position [7].

3) In the actual construction, the load of string is verified. The load of lifting the string uniformly is $290 \mathrm{kN}$, while the load of lowering the string uniformly is $220 \mathrm{kN}$, and the difference is $70 \mathrm{kN}$. Oil pipe wrench torque table shows $940 \mathrm{~N} \cdot \mathrm{m}$ when turning a string uniformly. It is found that the loads in lifting and lowering process are basically identical with calculated results [8]. The error of rotating torque is larger a little $(74 \mathrm{~N} \cdot \mathrm{m})$, through the analysis the influence of tubing string couplings diameter leads to a bit larger error but still in the acceptable range. The results above illustrate that calculation formula can meet the needs for all kinds of force and torque analysis.

4) In the construction using drill pipe, due to the large diameter of drill pipe couplings and large area of cross-sectional, the friction between the casing and drill pipe will further increase, that can have large effects on treatment success rate of all kinds of the conventional technology in the construction of slanted and horizontal wells [9].

\section{Conclusions}

1) Force analysis and calculation of workover string in the slanted and horizontal well are the basis of designing and checking string strength, selecting tools and determining operation parameters, which determine the operation safety and success of engineering accidence treatment.

2) Force analysis of workover string in the slanted and horizontal well must consider the factors of well structure, string combination, string load as well as the operation condition. The calculation of string load and the friction in every operation condition must consider the buckle deformation of the string and the constrain of the well structure and the fish.

3) Through the calculation methods and simplified formula of workover string load, deformation and stress in slanted and horizontal wells, the mechanics calculation about the downhole strings is made and the results are verified. Through the safety factor, the string assembly, tool selection and operation parameter optimization can be achieved, which can improve the safety and success rates of workover engineering accident treatment.

\section{References}

[1] Sui, M.C., Meng, K.L. and Du, L. (1999) Analysis of Friction on Drill String in Horizontal Drilling. China Petroleum Machinery, 27, 5-8.

[2] Dou, Y.H. and Zhang, F.X. (2007) Mechanical Analysis of Well Testing Down-Hole String in Deep Well with HTHP and Its Application. Drilling \& Production Technology, 30, 17-20.

[3] Song, X.H. and Du, H.Z. (2006) Study on Deep-Well Fracturing Strings. China Petroleum Machinery, 34, 72-74.

[4] Liu, Z.G. (1994) Analysis on the Downhole Stress of Slip Supported Packer. Oil Drilling \& Production Technology, 16, 53-59.

[5] Sheng, L.M. (2005) Tubing String Mechanics Analysis and Optimizing Design. Chengdu.

[6] Ding, P. and Yan, X.Z. (2005) Force Analysis of High Pressure Water Injection String. Petroleum Drilling Techniques, 33, 47-50. 
[7] Fisher, F.J. (1966) Analysis of Drilling String in Curved Bored Holes. SPE5071.

[8] Mitchell, R.F. (1986) Frictional Forces in Helical Buckling of Tubing. SPE13064.

[9] Salites, J. (1994) Experimental Study and Mathematical Modeling of Helical Buckling of Tubular in Inclined Well Bores. The University of Tulsa, Tulsa. 